\title{
Electronic Supplementary
}

\section{Information}




\section{A mononuclear cobalt complex for water oxidation:}

\section{New controversies and puzzles}

Rasoul Safdari, ${ }^{a}$ Mohammad Reza Mohammadi, ${ }^{\mathrm{b}, \mathrm{c}}$ Małgorzata Hołyńska, ${ }^{\mathrm{d}}$ Petko Chernev, ${ }^{\mathrm{b}, \mathrm{e}}$ Holger Dau and Mohammad Mahdi Najafpour*a,f,g

${ }^{a}$ Department of Chemistry, Institute for Advanced Studies in Basic Sciences (IASBS), Zanjan, 45137-66731, Iran

${ }^{b}$ Freie Universität Berlin, Fachbereich Physik, Arnimallee 14, 14195 Berlin, Germany

'University of Sistan and Baluchestan, Department of Physics, Zahedan, Iran, 9816745845

${ }^{d}$ Fachbereich Chemie and Wissenschaftliches Zentrum für Materialwissenschaften (WZMW), Philipps-Universität Marburg, Hans-Meerwein-Straße, D-35032 Marburg, Germany

eUppsala University, Department of Chemistry - Ångströmlaboratoriet, Lägerhyddsvägen 1, 75120 Uppsala, Sweden

${ }^{f}$ Center of Climate Change and Global Warming, Institute for Advanced Studies in Basic Sciences (IASBS), Zanjan, 45137-66731, Iran

${ }^{g}$ Research Center for Basic Sciences \& Modern Technologies (RBST), Institute for Advanced Studies in Basic Sciences (IASBS), Zanjan 45137-66731, Iran

*Corresponding author;

Phone: (+98) 243315 3201; E-mail: mmnajafpour@iasbs.ac.ir 


\section{Experimental}

\section{Materials}

All reagents and solvents were purchased from commercial sources and were used without further purification. Di(2-pyridyl)ketone, cobalt(II) perchlorate hexahydrate and fluorine-doped tin oxide coated glass (FTO) were purchased from the Sigma-Aldrich Company. Sodium carbonate was purchased from Merck Company.

\section{Synthesis of 1}

1 was synthesized by the previously reported method ${ }^{[1]}$.

Solution 1: $\mathrm{Co}\left(\mathrm{ClO}_{4}\right)_{2} \cdot 6 \mathrm{H}_{2} \mathrm{O}(0.5 \mathrm{mmol})$ was dissolved in $4 \mathrm{~mL}$ of acetonitrile.

Solution 2: $\mathrm{Na}_{2} \mathrm{CO}_{3}(0.5 \mathrm{mmol})$ and di(2-pyridyl)ketone $(1.0 \mathrm{mmol})(1: 2)$ were dissolved in a mixture of distilled water and acetonitrile $\left(\mathrm{V}_{\text {water }}: \mathrm{V}_{\text {acetonitrile }}=1: 1,8 \mathrm{~mL}\right)$ and the mixture was stirred until a clear solution was formed.

Subsequently, the solution 1 was slowly added dropwise to the solution $\mathbf{2}$ under strong stirring. The solution was strongly stirred for 3 hours and then filtered. The filtrate was kept in a $20 \mathrm{~mL}$ flask to allow slow evaporation at room temperature and the dark-red crystals of 1 were obtained after 5 days.

\section{Characterization}

Electrochemical experiments were performed using an EmStat ${ }^{3+}$ device from PalmSens (Netherlands). Cyclic voltammetry studies were carried out with a conventional threeelectrode setup in which $\mathrm{FTO}, \mathrm{Ag}|\mathrm{AgCl}| \mathrm{KCl}_{\text {sat }}$ and a platinum rod served as the working, 
reference and auxiliary electrodes, respectively. The distance between the two opposite sides of the FTO electrode was measured with a digital caliper MarCal 16ER model (Mahr, Germany). The temperature was measured with the Laserliner 082 device (Germany).

\section{XAS experiments}

After the bulk electrolysis of $\mathbf{1}$ for one hour at $1.20 \mathrm{~V}$ (vs. $\left.\mathrm{Ag}|\mathrm{AgCl}| \mathrm{KCl}_{\text {sat }}\right)$ using an FTO electrode we investigated this FTO electrode (FTO-A) in XAS experiments. The electrode was frozen by immersion in liquid nitrogen.

XAS measurements at the cobalt K-edge were performed at the KMC-3 beamline at the BESSY II synchrotron facility (Helmholtz-Zentrum Berlin, Germany) at $20 \mathrm{~K}$ in a liquidhelium cooled cryostat (Oxford-Danfysik). The angle between the film surface and the incident beam was approximately $45^{\circ}$. Fluorescence-detected X-ray absorption spectra at the cobalt K-edge were collected using a 13-element Ge detector (Ultra-LEGe, Canberra) installed perpendicular to the X-ray beam.

\section{X-ray diffraction studies}

Single crystal in form of an orange block was mounted on a Bruker Quest D8 diffractometer with CMOS detector. A multi-scan absorption correction was applied. Basic crystallographic data are collected in Table S1. 


\section{Refinement}

The crystal structure was solved by direct methods in SHELXS and refined with a fullmatrix technique in SHELXL-2014. O-bonded $\mathrm{H}$ atoms were found on difference Fourier map and subsequently, the cation hydroxyl $\mathrm{H}$ atoms were constrained with AFIX 147 constraints.

Additional maxima appearing in the vicinity of perchlorate $\mathrm{O}$ atoms were interpreted as a disorder of this anion. In this disorder the Cl1-O8 moiety position does not change, whereas the remaining three $\mathrm{O}$ atoms adopt two positions related by a rotation along the $\mathrm{Cl} 1-\mathrm{O} 8$ axis. The refined occupancies are $0.89(1)$ and $0.11(1)$, respectively. The minor-occupancy component was refined isotropically. SADI restraints were applied to keep the $\mathrm{Cl}-\mathrm{O}$ bond lengths similar. On the final difference Fourier map the highest maximum of $0.48 \mathrm{e} / \AA^{3}$ is located in the middle of C12-C13 bond. 


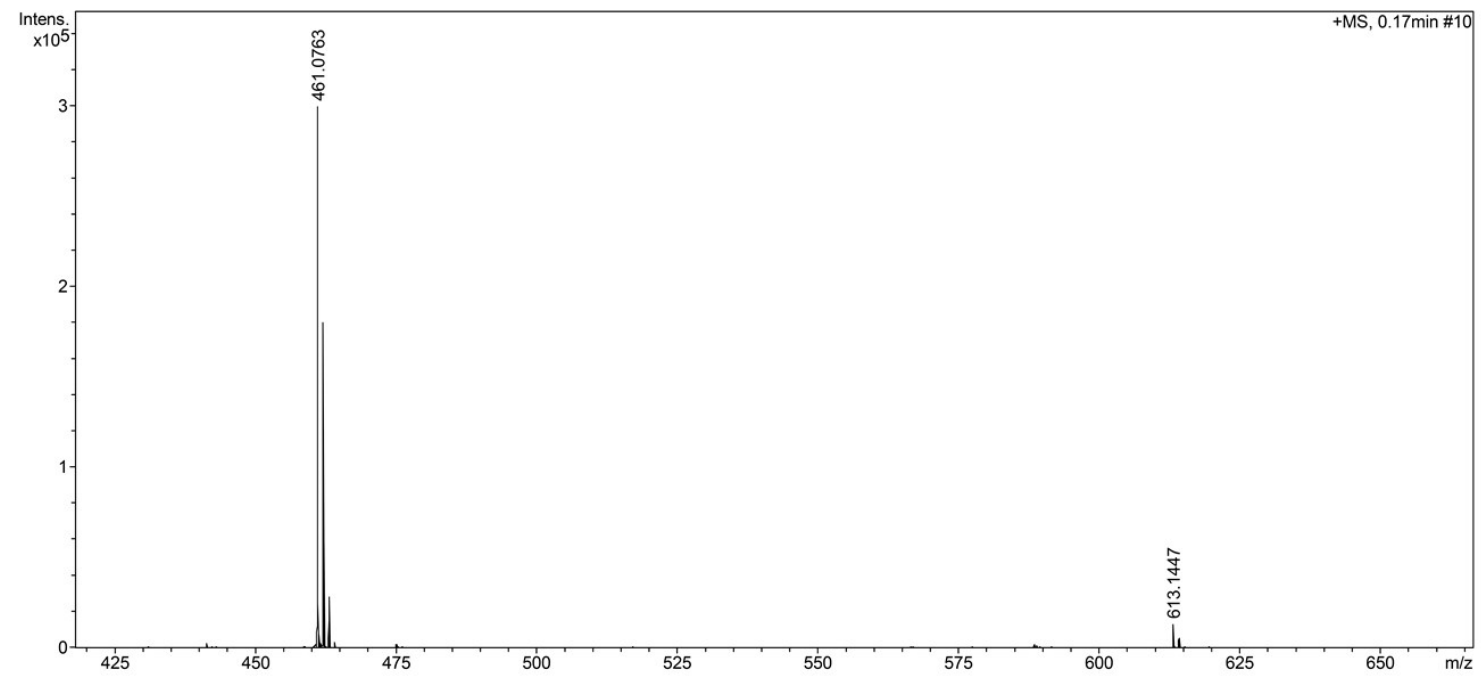

Fig. S1 ESI-Mass spectrum for 1. 


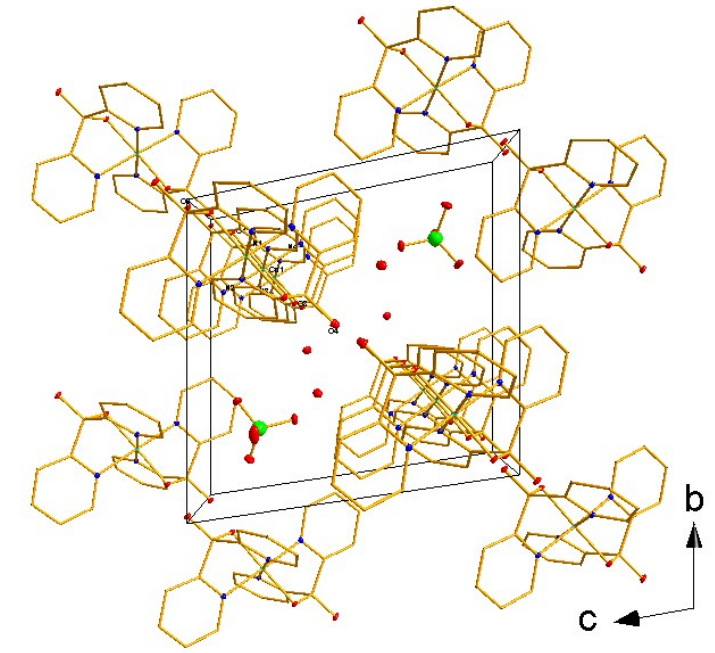

Fig. S2 Cation columns formed along the $a$ direction. The disordered anion minor component and $\mathrm{H}$ atoms are omitted for clarity. 


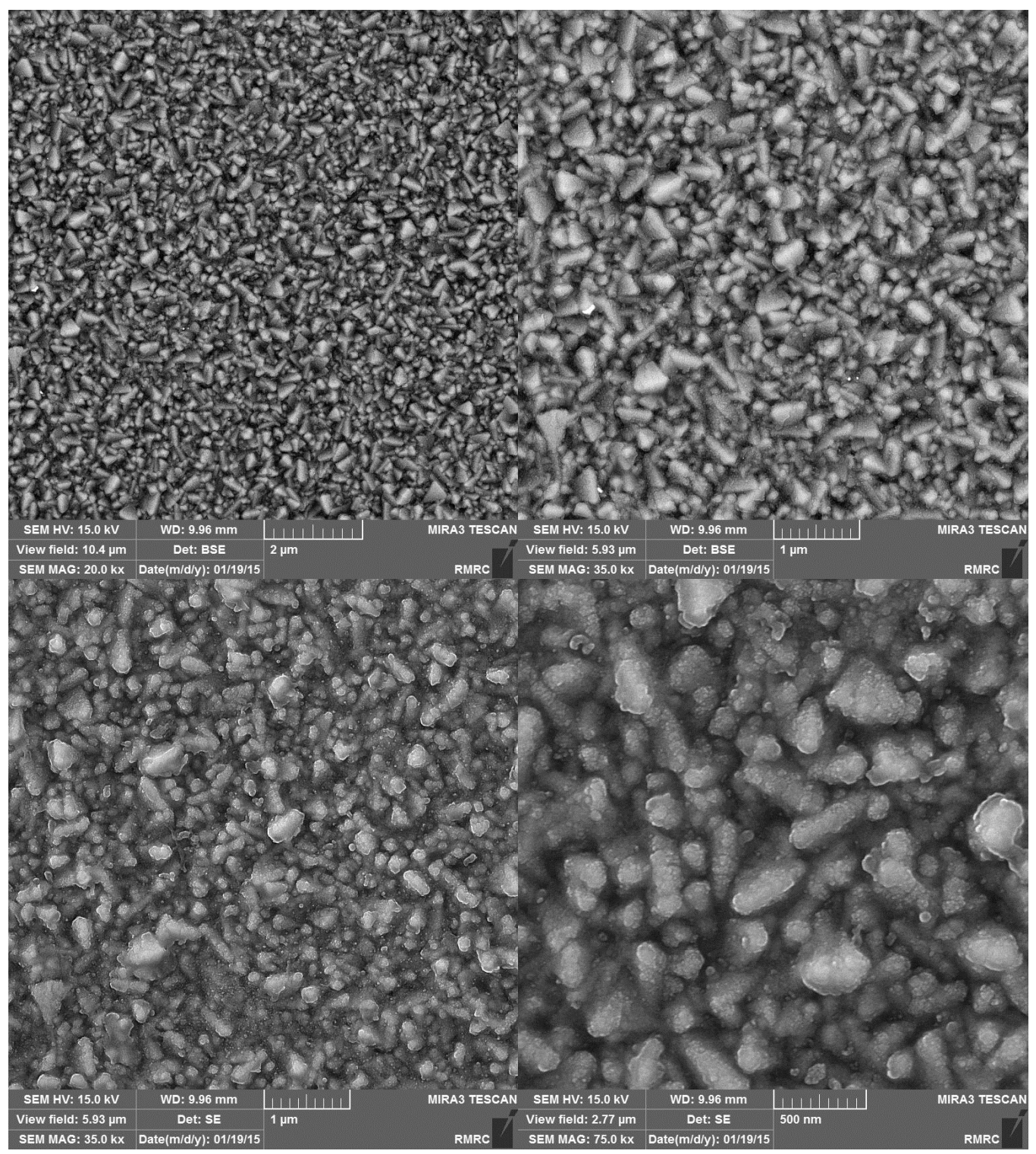

Fig. S3 SEM images for the fresh FTO. 


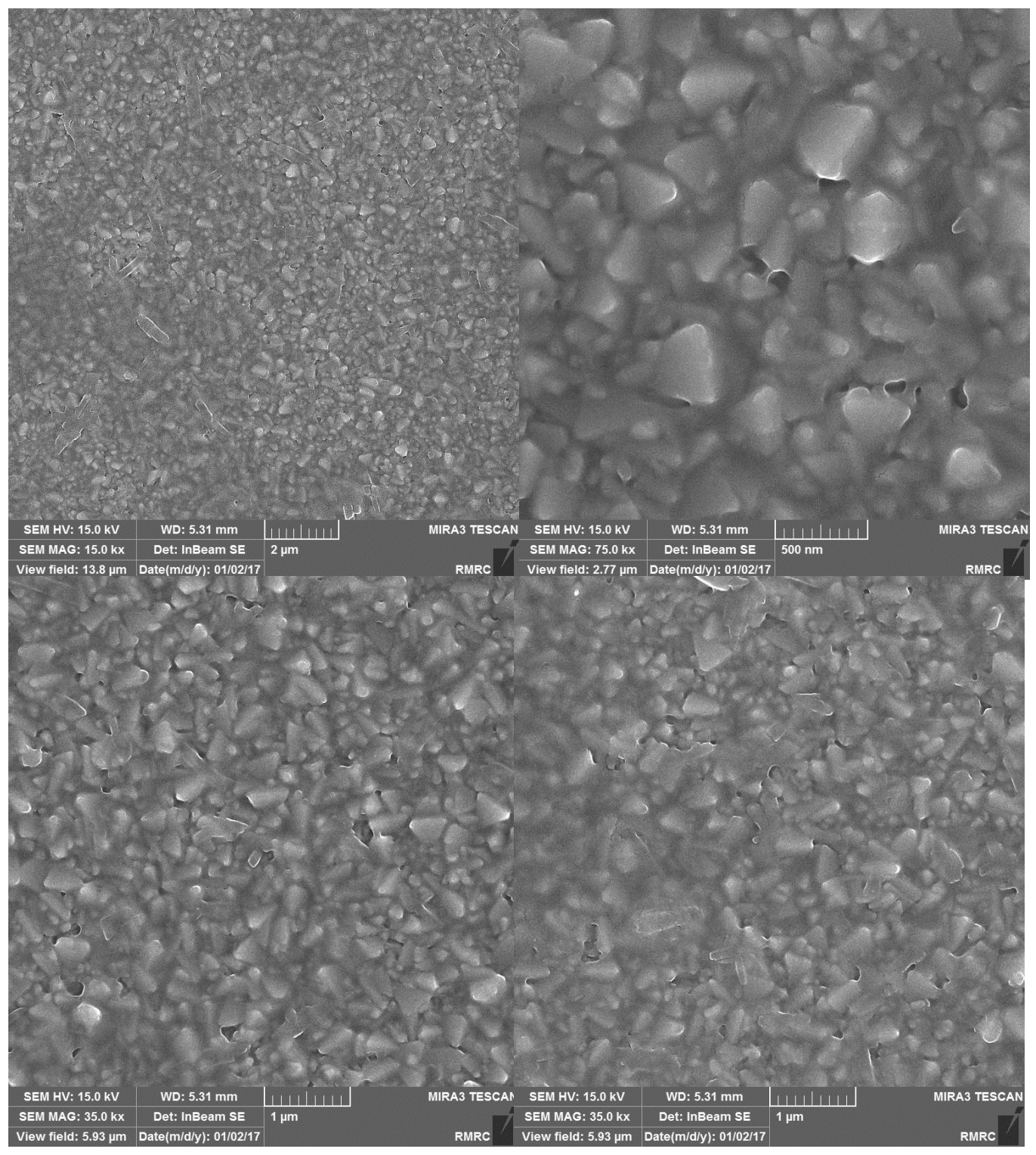

Fig. S4 SEM images for the film formed on the FTO-A electrode after 5.0 hours of electrolysis of 1 at (1.20 V vs. vs. $\mathrm{Ag} / \mathrm{AgCl})$ in $100.0 \mathrm{~mL}$ of sodium borate buffer solution (pH 9.0, $80 \mathrm{mM})$. 

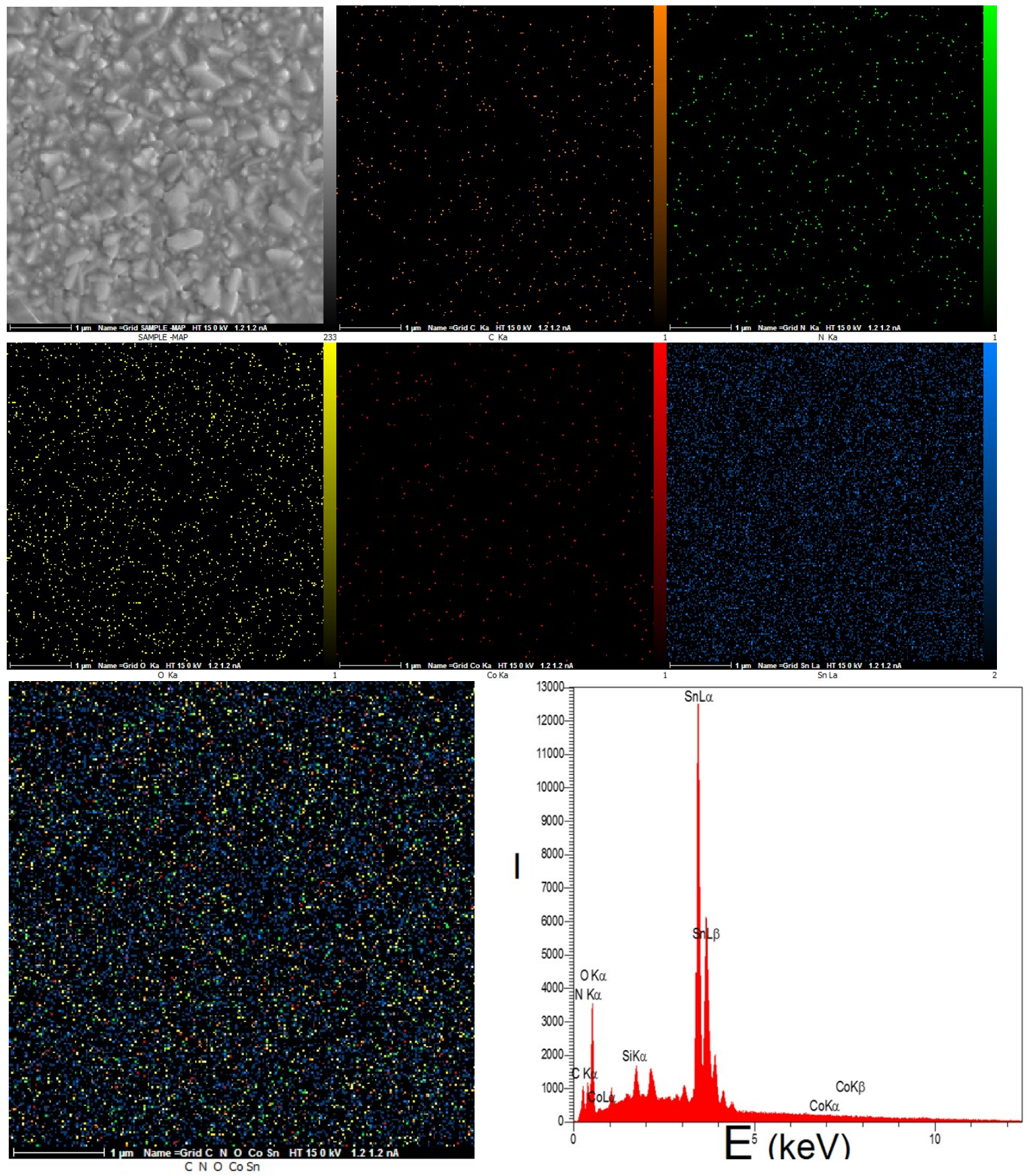

Fig. S5 EDX-SEM results for the film formed on the FTO-A electrode after 5.0 hours of electrolysis of 1 at ( $1.20 \mathrm{~V}$ vs. vs. $\mathrm{Ag} / \mathrm{AgCl})$ in $100.0 \mathrm{~mL}$ of sodium borate buffer solution $(\mathrm{pH}$ 9.0, $80 \mathrm{mM})$. 


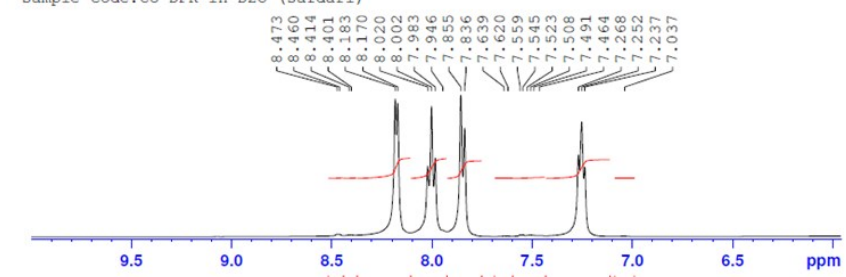

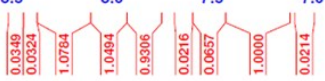

Sample code:Co-DPK $t=0$ in D2O (safdari)

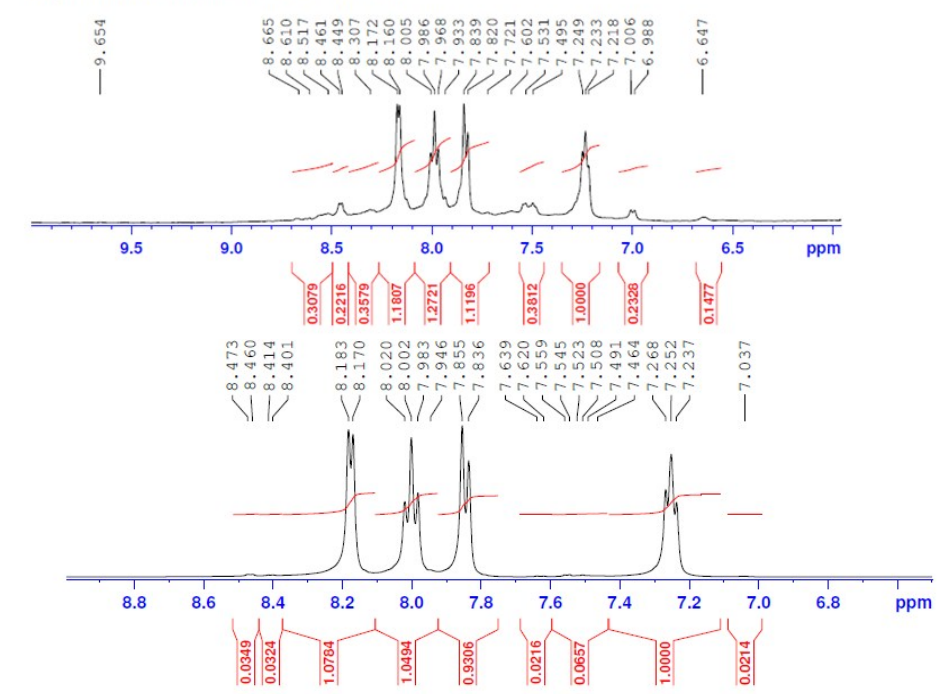

Sample code:Co-DPK $t=0$ in D2O (safdari)

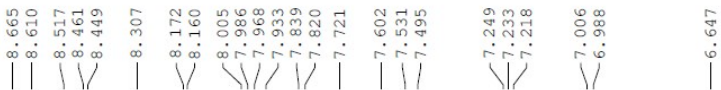

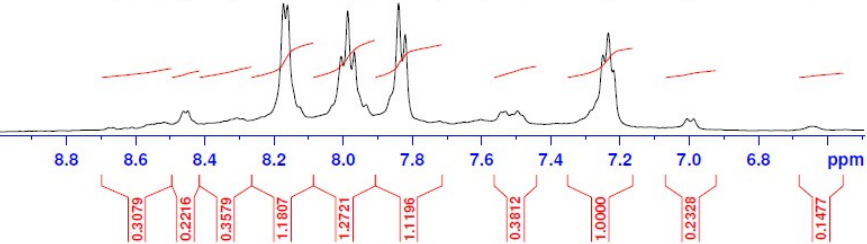

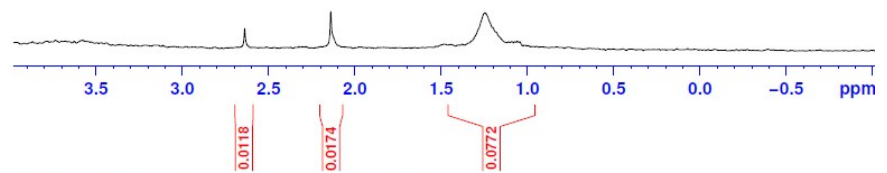

Sample code:Co-DPK $\mathrm{t}=0$ in D2O (safdari)
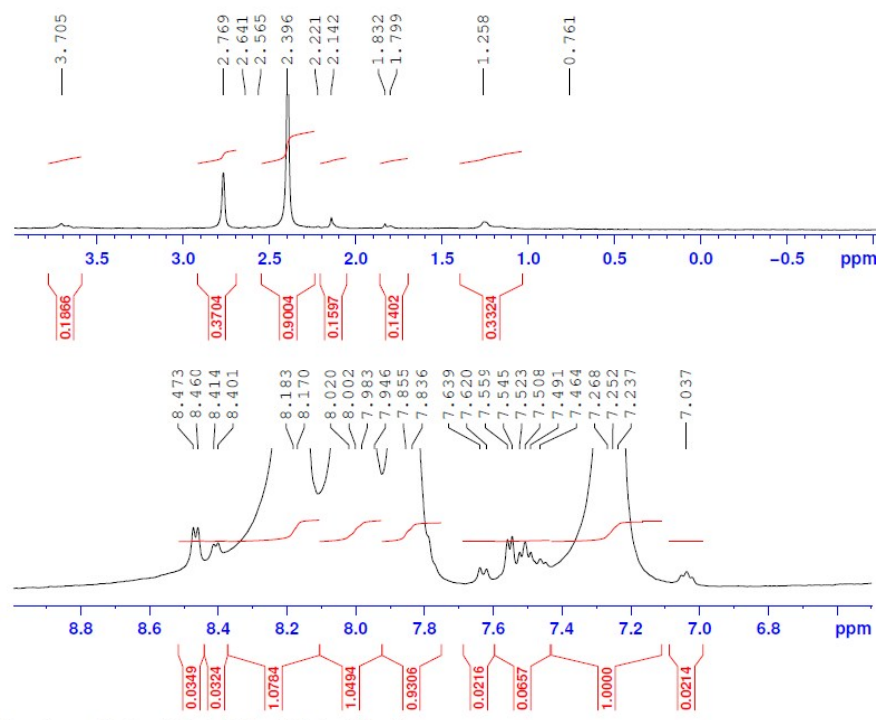

Sample code:Co-DPK $t=0$ in D2O (safdari)

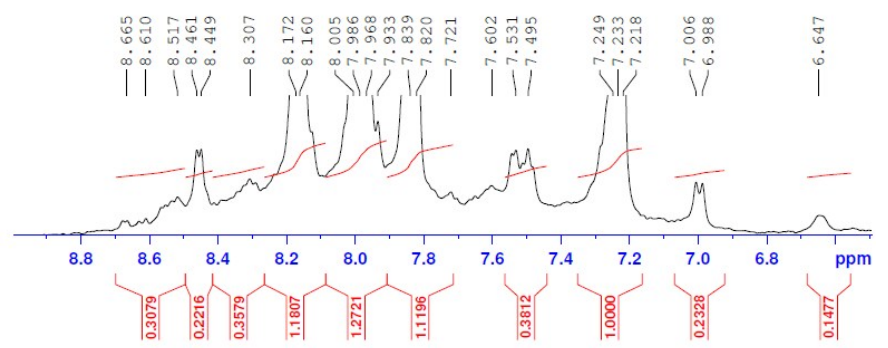

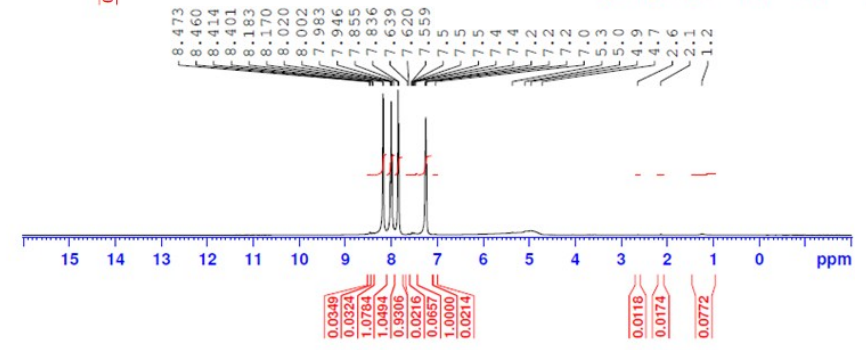

Sample code:Co-DPK t=0 in D2O (safdari)

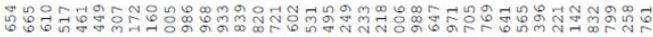

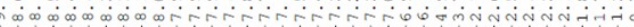

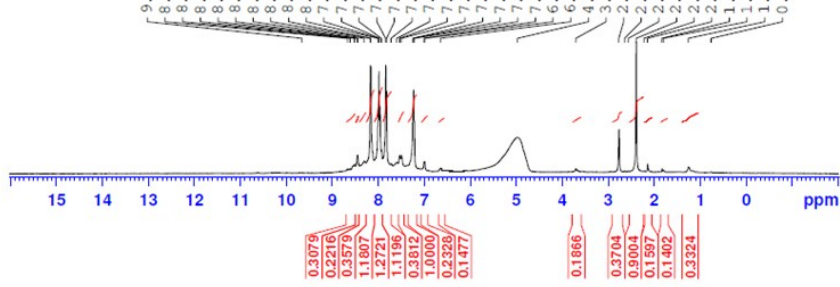

Fig. S6 ${ }^{1} \mathrm{HNMR}$ spectra for 1 before (below) and after 5.0 hours (top) amperometry ( $1.20 \mathrm{~V}$ vs. $\mathrm{Ag} / \mathrm{AgCl}$ ) of $1(20.0 \mathrm{mg})$ in $100.0 \mathrm{~mL}$ of sodium borate bufferlsolutions ( $\mathrm{pH} 9.0,80 \mathrm{mM})$. 


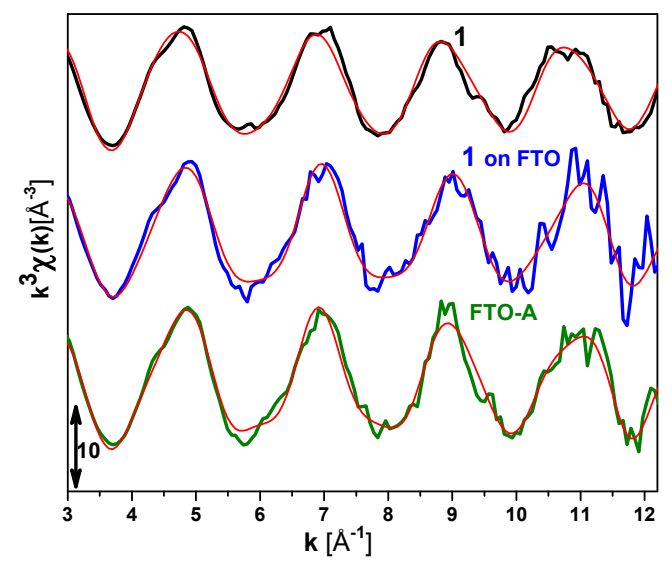

Fig. S7 $\mathrm{k}^{3}$-weighted $\chi(\mathrm{k})$ of $\mathbf{1}$ and $\mathbf{1}$ adsorbed on FTO as well as the operated compound on FTO (FTO-A) at $1.20 \mathrm{~V}$ for 5.0 hour in $100.0 \mathrm{~mL}$ of sodium borate buffer solutions ( $\mathrm{pH}$ 9.0, $80 \mathrm{mM}$ ) and the simulation results (red lines). XANES of adsorbed 1 on FTO and FTO-A at $1.2 \mathrm{~V}$ in $100.0 \mathrm{~mL}$ of sodium borate buffer solutions (pH 9.0, $80 \mathrm{mM}$ ). The fit parameters are given in Table 1.

\section{EXAFS simulations}

Simulations were performed using the in-house software package Sim $X^{[2]}$ and SimXLite. An EXAFS spectrum $\chi(k)$ is given by the sum of the contributions of $\mathrm{n}_{\text {shell }}$ 'atomic shells'. A 'shell' is a group of elements with identical atomic number and similar distances from the X-ray absorbing atom (e.g., six oxygen atoms surrounding the absorbing manganese ion). The EXAFS equation is mathematically defined by the following equation ${ }^{[3,4]}$ :

$$
\chi(k)=S_{\mathrm{o}}{ }^{2} \sum_{i}^{n_{\text {shell }}} A\left(R_{i}, k\right)_{i} N_{i} \exp \left(-2{\sigma_{i}}^{2} k^{2}\right) \sin \left(2 k R_{i}+\phi_{i}\right)
$$

where $S_{\mathrm{o}}{ }^{2}$ is the amplitude reduction factor, $A(\text { Rii,k) })_{i}$ is a factor that includes the scattering amplitude and mean-free-path of the photo-electron, $\phi_{i}$ the phase correction, $N_{i}$ the number of atoms in the $i^{\text {th }}$ atomic shell, $\sigma_{i}$ the Debye-Waller parameter of the $i^{\text {th }}$ atomic shell, and $R_{i}$ the (average) distance between the X-ray 
absorbing atom and the atoms of the $i^{\text {th }}$ atomic shell. The functions $A$ and $\phi$ were obtained herein from ab-initio calculations using Feff $9.05{ }^{[5]}$, using coordinates from the molecular structure of $\mathbf{1}$.

For conversion of the energy axis to a k-vector axis, an $E_{0}$ of $7709 \mathrm{eV}$ was used. Curvefitting of the data was accomplished within a k-range of $2.5 \AA^{-1}$ to $13 \AA^{-1}$. The amplitude reduction factor, $S_{0}{ }^{2}$, was 0.7 . Parameter error estimation was performed as described in Ref. 6.

As it is well known, distance $R$ is not an independent parameter but strongly coupled with the $\Delta \mathrm{E}_{0}$ value. Similarly, the coordination numbers $N$ and Debye-Waller parameters $\sigma$ are also coupled and need to be separated from each other. Therefore, we first determined $\Delta \mathrm{E}_{0}$ and $\sigma$ from a fit to the initial compound $\mathbf{1}$ in which the coordination numbers were fixed to the values expected from the molecular structure of 1 (sum of $N$ for $\mathrm{Co}-\mathrm{O}_{\text {short }} / \mathrm{N}_{\text {short }}$ shells equal to 6 , and sum of $N$ for Co-C shells equal to 10$)$. We then used these $\Delta \mathrm{E}_{0}$ and $\sigma$ values for the fit of the sample after operation. 
Table S1 Basic crystallographic data.

\begin{tabular}{|c|c|}
\hline & 1 \\
\hline Formula & $\mathrm{C}_{22} \mathrm{H}_{18} \mathrm{CoN}_{4} \mathrm{O}_{4} \cdot \mathrm{ClO}_{4} \cdot 2\left(\mathrm{H}_{2} \mathrm{O}\right)$ \\
\hline Formula weight & 596.81 \\
\hline Temperature [K] & $100(2)$ \\
\hline$\lambda[\AA]$ & 0.71073 \\
\hline Crystal system & Triclinic \\
\hline Space group & $\mathrm{P}^{\overline{1}}$ \\
\hline a $[\AA]$ & $8.445(3)$ \\
\hline$b[\AA]$ & $11.908(3)$ \\
\hline$c[\AA]$ & $12.414(4)$ \\
\hline$\alpha\left[^{\circ}\right]$ & $99.74(3)$ \\
\hline$\beta\left[^{\circ}\right]$ & $103.51(3)$ \\
\hline$Y\left[^{\circ}\right]$ & $90.24(3)$ \\
\hline$V\left[\AA^{3}\right]$ & $1195.1(7)$ \\
\hline$Z, \rho_{\text {calc }}\left[\mathrm{g} \mathrm{cm}^{-3}\right]$ & $2,1.658$ \\
\hline$\mu\left[\mathrm{mm}^{-1}\right]$ & 0.90 \\
\hline$F(000)$ & 612 \\
\hline Crystal size $[\mathrm{mm}]$ & $0.64 \times 0.24 \times 0.15$ \\
\hline$\theta$ range $[\stackrel{0}{]}]$ & $2.2-30.1$ \\
\hline rflns: total /unique & $60965 / 7036$ \\
\hline Abs. corr. & multi-scan \\
\hline $\begin{array}{l}\text { Min., max. transmission } \\
\text { factors }\end{array}$ & $0.600,0.876$ \\
\hline Data/restraints/params & $7036 / 21 / 376$ \\
\hline GOF on $\mathrm{F}^{2}$ & 1.02 \\
\hline $\mathrm{R}_{1}[\mathrm{I}>2 \sigma(\mathrm{I})]$ & 0.026 \\
\hline $\mathrm{wR}_{2}$ (all data) & 0.076 \\
\hline Max., $\min . \Delta \rho_{\text {elect }}\left[\mathrm{e} \AA^{-3}\right]$ & $0.48,-0.54$ \\
\hline
\end{tabular}


Table S2 Selected bond lengths and bond angles [ $\left[\AA{ }^{\circ}{ }^{\circ}\right.$.

\begin{tabular}{|c|c|c|c|}
\hline $\mathrm{Co1}-\mathrm{O} 3$ & 1.8859 (11) & Co1-N3 & $1.9302(12)$ \\
\hline Co1-01 & $1.8902(11)$ & $\mathrm{O} 1-\mathrm{C} 6$ & 1.4047 (14) \\
\hline Co1-N4 & $1.9133(12)$ & $\mathrm{O} 2-\mathrm{C} 6$ & 1.3759 (14) \\
\hline Co1-N1 & 1.9159 (11) & $\mathrm{O} 3-\mathrm{C} 17$ & $1.4062(14)$ \\
\hline Co1-N2 & $1.9238(12)$ & O4-C17 & 1.3799 (14) \\
\hline $\mathrm{O} 3-\mathrm{Co} 1-\mathrm{O} 1$ & $178.44(3)$ & $\mathrm{N} 4-\mathrm{Co} 1-\mathrm{N} 2$ & $178.45(4)$ \\
\hline $\mathrm{O} 3-\mathrm{Co} 1-\mathrm{N} 4$ & $83.33(5)$ & N1-Co1-N2 & $87.92(5)$ \\
\hline $\mathrm{O} 1-\mathrm{Co} 1-\mathrm{N} 4$ & $95.36(5)$ & $\mathrm{O} 3-\mathrm{Co} 1-\mathrm{N3}$ & $82.91(5)$ \\
\hline $\mathrm{O} 3-\mathrm{Co} 1-\mathrm{N} 1$ & $95.90(5)$ & $\mathrm{O} 1-\mathrm{Co} 1-\mathrm{N} 3$ & $97.93(5)$ \\
\hline $\mathrm{O} 1-\mathrm{Co} 1-\mathrm{N} 1$ & $83.26(5)$ & $\mathrm{N} 4-\mathrm{CO} 1-\mathrm{N} 3$ & $88.82(5)$ \\
\hline $\mathrm{N} 4-\mathrm{Co} 1-\mathrm{N} 1$ & $90.78(5)$ & $\mathrm{N} 1-\mathrm{Co} 1-\mathrm{N} 3$ & $178.78(4)$ \\
\hline $\mathrm{O} 3-\mathrm{CO} 1-\mathrm{N} 2$ & $97.65(5)$ & $\mathrm{N} 2-\mathrm{Co} 1-\mathrm{N} 3$ & $92.49(5)$ \\
\hline $\mathrm{O} 1-\mathrm{Co} 1-\mathrm{N} 2$ & 83.64 (5) & & \\
\hline
\end{tabular}


Table S3 Hydrogen bonding parameters $\left[\AA \AA{ }^{\circ}\right]$.

\begin{tabular}{|c|c|c|c|c|}
\hline$D-\mathrm{H} \cdots A$ & $D-\mathrm{H}$ & $H \cdots A$ & $D \cdots A$ & $D-H \cdots A$ \\
\hline $\mathrm{O} 1 W-\mathrm{H} 1 W 1 \cdots \mathrm{O} 8^{\mathrm{i}}$ & $0.81(3)$ & $2.15(3)$ & $2.942(2)$ & $167(2)$ \\
\hline $\mathrm{O} 2 W-\mathrm{H} 1 W 2 \cdots \mathrm{O}^{\mathrm{i}}$ & $0.78(2)$ & $1.90(2)$ & $2.6706(16)$ & $172(2)$ \\
\hline $\mathrm{O} 2 W-\mathrm{H} 2 \mathrm{~W} 2 \cdots \mathrm{O} 8$ & 0.77 (3) & $2.12(3)$ & $2.8938(18)$ & $179(3)$ \\
\hline $\mathrm{O} 2-\mathrm{H} 2 \mathrm{O} \cdots \mathrm{O} 1^{\mathrm{ii}}$ & 0.84 & 1.78 & $2.6181(14)$ & 174 \\
\hline $\mathrm{O} 4-\mathrm{H} 4 \mathrm{O} \cdots \mathrm{O} 2 \mathrm{~W}$ & 0.84 & 1.76 & $2.5929(15)$ & 173 \\
\hline $\mathrm{C} 2-\mathrm{H} 2 \cdots \mathrm{O} 1 W^{i}$ & 0.95 & 2.65 & $3.344(2)$ & 130 \\
\hline $\mathrm{C} 4-\mathrm{H} 4 \cdots \mathrm{O} 2^{\mathrm{iii}}$ & 0.95 & 2.63 & $3.225(2)$ & 121 \\
\hline $\mathrm{C} 10-\mathrm{H} 10 \cdots \mathrm{O}^{\mathrm{i}}$ & 0.95 & 2.62 & $3.142(3)$ & 115 \\
\hline $\mathrm{C} 11-\mathrm{H} 11 \cdots \mathrm{O}^{\mathrm{i}}$ & 0.95 & 2.42 & $3.048(2)$ & 124 \\
\hline $\mathrm{C} 12-\mathrm{H} 12 \cdots \mathrm{O}^{\mathrm{iv}}$ & 0.95 & 2.63 & $3.529(2)$ & 158 \\
\hline $\mathrm{C} 12-\mathrm{H} 12 \cdots 066^{\mathrm{iv}}$ & 0.95 & 2.59 & 3.110 (14) & 115 \\
\hline $\mathrm{C} 12-\mathrm{H} 12 \cdots \mathrm{O} 2^{\mathrm{ii}}$ & 0.95 & 2.59 & 3.2171 (17) & 124 \\
\hline $\mathrm{C} 15-\mathrm{H} 15 \cdots 4^{v}$ & 0.95 & 2.60 & $3.498(2)$ & 159 \\
\hline $\mathrm{C} 19-\mathrm{H} 19 \cdots \mathrm{O} 1 W^{N}$ & 0.95 & 2.66 & $3.252(2)$ & 121 \\
\hline $\mathrm{C} 22-\mathrm{H} 22 \cdots O 7^{\mathrm{vi}}$ & 0.95 & 2.37 & $3.314(2)$ & 174 \\
\hline $\mathrm{C} 22-\mathrm{H} 22 \cdots 077^{\mathrm{vi}}$ & 0.95 & 2.45 & $3.356(13)$ & 158 \\
\hline
\end{tabular}

(i) $-x+1,-y+1,-z+1$

(ii) $-x+1,-y+2,-z+2$

(iii) $-\mathrm{x}+2,-\mathrm{y}+2,-\mathrm{z}+2$

(iv) $x, y, z+1$

(v) $-x,-y+1,-z+1$

(vi) $-\mathrm{x}+1,-\mathrm{y}+2,-\mathrm{z}+1$ 


\section{Reference}

[1] Y. Zhao, J. Lin, Y. Liu, B. Ma, Y. Ding and M. Chen, Chem. Commun., 2015, 51, 17309.

[2] J. Dittmer, Ph.D. Thesis, Christian-Albrechts-Universität (Kiel, Germany), 1999.

[3] J. E. Penner-Hahn, Coord. Chem. Rev., 1999, 1101, 190.

[4] J. J. Rehr and R. C. Albers, Rev. Mod. Phys., 2000, 72, 621.

[5] a) A. L. Ankudinov, B. Ravel, J. J. Rehr and S. D. Conradson, Phys. Rev. B, 1998, 58,

7565; b) J. J. Rehr, J. J. Kas, M. P. Prange, A. P. Sorini, Y. Takimoto and F. Vila, C. $R$.

Physique, 2009, 10, 548.

[6] M. Risch, K. Klingan, J. Heidkamp, D. Ehrenberg, P. Chernev, I. Zaharieva and H. Dau, Chem. Commun., 2011, 47, 11912. 